\title{
1015 TRUST IN GOD
}

C A Dixon* Correspondence to Cincinnati Children's Hospital and Medical Center, 3333 Burnet Avenue, MLC 2008 Cincinnati, Ohio 45229, USA

\subsection{6/ip.2010.029215.1015}

Photo number: 1 Photo location: Ghana photo description: a powerful rear-view image of a large blue truck carrying 40+ standing people and $10+$ sitting people on the top rack. Across the back of the truck in large red and white letters, it is written 'Trust in God'. Photo story: this photograph was taken in Northern Ghana, summer 2009. Working as a paediatric emergency medicine physician in the country to help advance emergency care during that time, 1 week earlier I experienced mass trauma first-hand. An excerpt from an email sent home on that day. I had a very difficult night one night ago. Got a text from a nurse stating "deadly in need of help" I walked briskly back to the hospital. As I came upon the hospital I heard the all too familiar wailing of severe loss. I began running through the corridors now blood leading my steps, standerbyers calling out and weeping. I rounded the corner into the small emergency ward, and bodies were strewn about all over - on beds, benches, and floors. Blood was everywhere... victims were sobbing and screaming. A small bus stuffed with far too many people had lost control on the road and overturned down a hill. All in all, 20 victims, multiple amputations, head injuries, uncountable other injuries, and one death all versus three nurses, a couple of aids, and myself." Now 1 week later, following behind this truck of sardine-packed people, the reality of the real-life trauma and outcomes facing these individuals was clear. Under my breath I also prayed that they 'trust' in someone. 